NUKHBATUL 'ULUM : Jurnal Bidang Kajian Islam

Vol. 4, No. 1 (2018) : Hal. $61-69$

Website: https://journal.stiba.ac.id

ISSN : 2685-7537 (online) 2338-5251 (Printed)

\title{
FUNGSI DAN KEDUDUKAN KATA GANTI (DHAMI $R)$ DALAM ILMU SHARF
}

\section{Zulfiah Syam}

Sekolah Tinggi Ilmu Islam dan Bahasa Arab (STIBA) Makassar, Jl. Inspeksi PAM Manggala-Antang Makassar

E-mail: zulfiah@stiba.ac.id

\begin{tabular}{ll} 
Keywords : & ABSTRACT \\
\cline { 2 - 3 } ism, dhamir, sharf & Arabic is the language of the Al-Qur'an which was sent down by \\
Allah Almighty. Arabic is a language that has rich vocabularies and \\
it is a language known for its complex grammatical structure \\
(qawa'ed). In order to understand arabic properly, the understanding \\
the grammar of the language is necessary. It is an obligation upon the \\
Moslem to learn Arabic for better comprehension in Qur'anic text. In \\
this research, the author examined one of the subjects in Sharf \\
(Morphology) that is Ism Dhamitr (Pronoun). Ism Dhamiur are \\
words used as the pronoun either for the first person, the pronoun for \\
the second person or the pronoun for a third person. In this research, \\
the author also outlined the subject by giving examples of sentences in \\
aform of a chart or a column so that it will be easy to understand from \\
the explanation and it would argue on people thought on the \\
complexity of learning Arabic. The author expected that this research \\
could be additional knowledge and references in learning the grammar \\
of Arabic.
\end{tabular}




\section{NUKHBATUL 'ULUM : Jurnal Bidang Kajian Islam}

Vol. 4, No. 1 (2018) : Hal. $61-69$

Website: https://journal.stiba.ac.id

ISSN : 2685-7537 (online) 2338-5251 (Printed)

\section{PENDAHULUAN}

Banyak yang memahami bahwa kaidah-kaidah (qawäid) Bahasa Arab secara umum sangatlah susah untuk dipahami, kecuali mereka yang secara takhașșus belajar di ma'had atau pesantren-pesanteren yang secara mendetail diajarkan dan dipelajari kaidah-kaidah bahasa tersebut. Jika di kaji dari sebab keyakinan akan rumitnya pembelajari kaida-kaidah Bahasa Arab adalah karena mempelajarinya secara parsial tanpa di dasari dengan metode pembelajaran secarah sempurna dan tepat.

Kaidah-kaidah (qawāid) Bahasa Arab itu terbagi atas dua macam yaitu kaidahkaidah Ilmu Nahwu ${ }^{1}$ dan kaidah-kaidah Ilmu Sharf. ${ }^{2}$ Kaidah-kaidah yang dipelajari pada awal pembahsan Ilmu Sharf seperti d̦amīr, tașrīf, mașdar dan lain-lain.

Untuk memahami kaidah-kaidah Bahasa Arab tersebut dengan baik, harus ada silsilah mutarābițah, mutadarrijah, mutataābi'ah, syamilah, al-mutakāmilah. Dan yang terpenting adalah penerapan yang baik (jayyid) disaat berlangsungnya proses belajarmengajar tersebut.

Dari latar belakang masalah di atas, maka dapat dirumuskan beberapa rumusan masalah pada tulisan ini, untuk dibahas serta dikaji berkaitan pembahasan awal dari Ilmu Sharf. Pembahasan tersebut adalah sebagai berikut.

1. Apa yang dimaksud dengan dhamī?

2. Bagaimana bentuk-bentuk dhamī?

3. Berapa macam pembagian bamī?

\section{PEMBAHASAN}

\section{A. Damīr}

1. Pengertian Damīr

Damī adalah kata ganti, kata yang digunakan sebagi penganti ism (kata benda), bentuk fluralnya adalah ḍamair. Ada juga yang mengartikan ḍamīr atau ḍamäir yaitu nama dan lafal bahasa Arab yang menunjukkan sebagai sifat, atau kata ganti orang pertama atau kata ganti orang ke dua atau kata ganti orang ke tiga, sebagai kata ganti benda untuk meringkas suatu kalimat. ${ }^{4}$ Lafal-lafal yang digunakan dalam suatu dialek untuk menunjuk pada seseorang yang telah diketahui, lafal pengganti dari menyebutkan mereka sebagai ringkasan. ${ }^{5}$

Damīr meupakan ism (kata benda) yang berfungsi untuk menggantikan penyebutan kata-kata yang banyak dan menempati kata-kata itu dengan sempurna tanpa merubah makna yang dimaksud ḍamir (kata ganti orang) dalam bahasa Arab memeliki 14 bentuk. $^{6}$

\footnotetext{
${ }^{1}$ Ilmu Nahwu ialah ilmu tentang kaidah-kaidah Bahasa Arab yang dengannya dapat diketahui kedudukan suatu kata dalam susunan kalimat (al-Jumlah), dan dapat diketahuai harakat terakhir, dan dapat diketahui bagaimana cara meng'irabkan kata tersebut. (Lihat Fuād Ni'mah, Mulahkaṣ Qawāid al-Lugah alArabiyyah (t. Cet: Beirut: Dār At-Ṡqāfah Al-Islāmiyyah, tt), h. 17

2 Ilmu Sharf ialah mengubah suata akar kata Bahasa Arab ke dalam bentuk yang berbeda-beda.

${ }^{3}$ Asri Ibnu Tsani Djali, Sharf Lughatuna (Cet. II; asripublisher Jawa Barat, 2010), h. 3

4 http://mawdoo3.com. (diakses tanggal, 5 Februari 2018). Lihat Fuād Ni'mah, 17

${ }^{5}$ http://forums.way2allah.com/forum. (diakses tanggal, 5 Februari 2018).

6 Muhammad Muhhyidin Abdul Hamid, At-Tuhfa As-Saniyah (syarah Ajjurumiyah). Trjh. Abu AbdillahSalim bin Subaid (Tegal : Ash-Shafmedia, 2008), h. 177
} 
Jadi dari pengertian diatas dapat dipahami, bahwa ḍamìr terbagi menjadi beberapa bentuk perubahan, yaitu antara lain:

a. Damīr Gäib (Kata ganti orang ke-III) : orang yang dibicarakan, yaitu:
1. ه : dia, ia, beliau [L]
2. Lo : mereka dua [L]
3. ه : mereka lebih dari dua [1]
4. : : dia, ia, beliau [p]
5. ه : mereka dua [p]
6. : : mereka lebih dari dua [p]

b. Dhamīr Mukhätab (Kata ganti orang ke-II) : orang yang diajak bicara, yaitu:
1. : : : kamu, engkau [1]
2. : : : : : : : أنتمات
3. : : : : : : :
4. : : : kamu, engkau [p]
5. : : : kalaian berdua [p]
6. : : mereka lebih dari dua [p]

c. Dhamīr Mutakallim (Kata ganti orang ke-I) : orang yang berbicara, yaitu:

1. : saya $[1 / \mathrm{p}]$

2. ن : kami, kita $[\mathrm{l} / \mathrm{p}]$

Dalam Bahasa Arab, kata ganti akan lebih kompleks, karena akan ada istilah kata ganti untuk laki-laki, kata ganti untuk perempuan, kata ganti tunggal, jamak, dan dua orang. ${ }^{7}$ Atau dalam istilah Bahasa Arab dikenal dengan liḍakar, lilmuannas, lilmufrad, lilmustanna dan liljama'. Penjelasan ini tergambar pada bentuk-bentuk perubahan dhamī di atas.

Selain sebagai kata ganti, dhamīr dijadikan acuan untuk perubahan bentuk fi'il (kata kerja). ${ }^{8}$ Dimana akan dibahas pada bab selanjutnya dalam pembahasan ini.

\section{Pembagian Dhamīr}

Dalam ilmu Bahasa Arab, ism dhamīritu secara umum terbagi menjadi dua:

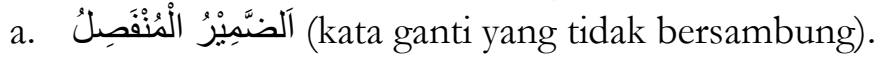

Dhamīr Munfașil yaitu dhamīr (kata ganti) yang tidak bersambung dengan suatu suku kata di depannya. Dhamīr Munfashil terbagi menjadi 12 (dua belas) antara lain:

1) هو (dia, ia. beliau [1] untuk orang ketiga (yang dibicarakan), tunggal (mufrad) ${ }^{9}$, mudrakear.

2) Lهَ (mereka berdua $[1 / \mathrm{p}])$ : untuk orang ketiga, ganda $\left(\right.$ mutsanna) ${ }^{10}$, baik mudzakekar maupun muannas.

3) هُمْ (mereka lebih dari dua [banyak laki-laki]): untuk orang ketiga, jamak ${ }^{11}$, mudzakkar.

4) هِيَ (dia, ia, beliau [p]): untuk orang ketiga, mufrad, muannas.

${ }^{7}$ Abu Razin dan Ummu Razin, IImu Sharaf Untuk Pemula (Cet.III; Jakarta: Maktabah BISA, 2017), h. 13-

${ }^{8}$ Asri Ibnu Tsani Djalil, h. 3

${ }^{9}$ Ism mufrad ialah kata benda yang menunjukkan satu benda. Lihat Fuād Ni'mah, 21

${ }^{10}$ Ism munsianna ialah kata benda yang menunjukkan dua benda. Lihat Fuād Ni'mah, 21

${ }^{11}$ Ism jama' ialah kata benda yang menunjukkan lebih dari dua benda (banyak). Lihat Fuād Ni'mah, 
NUKHBATUL 'ULUM : Jurnal Bidang Kajian Islam

Vol. 4, No. 1 (2018) : Hal. $61-69$

Website: https://journal.stiba.ac.id

ISSN : 2685-7537 (online) 2338-5251 (Printed)

5) هُنَّ (mereka lebih dari dua [banyak perempuan]): untuk orang ketiga, jamak, muannas.

6) أَنْنَ (kamu, engkau [1]): untuk orang kedua (lawan bicara), mufrad, mudzakkar.

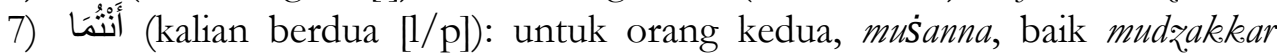
maupun muannas.

8) أَنْيُم (kalian lebih dari dua [banyak laki-laki]): untuk orang kedua, jamak, mudzakear.

9) أَنْتِ (kamu, engkau [p]): untuk orang kedua, mufrad, muannaś.

10) أَنْتُنَّ (kalian lebih dari dua [banyak perempuan]): untuk orang kedua, jamak, muannas.

11) أَنَا (Saya [1/p]): untuk orang pertama (si pembicara) mufrad, baik mudzakkar maupun muannas.

12) نحن (kami, kita [l/p]): untuk orang pertama, jamak, baik mudzakkear maupun muannats; digunakan juga untuk orang pertama tunggal (mufrad) yang mengagungkan dirinya.

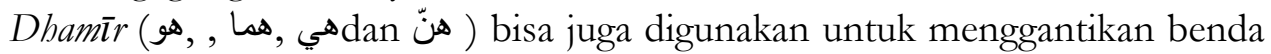
(selain manusia), namun tidak dijelaskan dalam pembahasan ini.

Harakat dari semua kata ganti ini tetap, tidak berubah-ubah, bagiamanapun kedudukan kata tersebut dalam kalimat. Kata-kata yang seperti ini dikenal dengan istilah mabni (مبني). Lawan mabni adalah mu'rab (معرب).

Contoh kalimat mu'rab:

a) Bentuk mufrad (tunggal)

\begin{tabular}{|c|c|}
\hline الترجمة & الجملة \\
\hline 1. telah datang ustadzah & 1 ـ جائتْ الأستاذةُ \\
\hline 2. saya melihat ustadzah & 2. ــ رأيتُ الأستاذةً \\
\hline
\end{tabular}

b) Bentuk muśanna (dua)

\begin{tabular}{|c|c|}
\hline 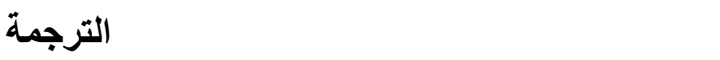 & 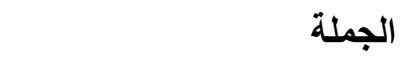 \\
\hline 1. dua mahasiswi itu cantik & 1 ـ الطالبنان جميلتان \\
\hline 2. sesungguhnya dua mahasiswi itu cantik & 2 ـ إنّ الطالبتين جميلتين \\
\hline $\begin{array}{l}\text { 3. kelas yang bagus itu punya dua } \\
\text { mahasiswi cantik itu }\end{array}$ & 3. جميلتين الفصل الجميل للطالبتين \\
\hline
\end{tabular}

${ }^{12}$ Fuād Ni'mah, h. 17

Dalam Qaidah disebutkan:

Kalimat atau lafal dari segi fungsinya terbagi dua : mabni dan mu'rab.

1. Kalimat yang mabni ialah kalimat yang akhirnya tetap pada satu keadaan/bacaan didalam segala susunan jumlah. Lihat Irbabullubab dan Dja'far Amir, Nahwu \& Sharaf (t. Cet; Semarang: C.V. Toha Putra, 1970), h. 6

2. Kalimat yang $m u^{\prime} r a b$ ialah kata yang berobah-obah akhirnya atau Kata yang tanda baca akhirnya berubah sesuai kedudukannya pada suatu kalimat. Lihat Irbabullubab dan Dja'far Amir, Nahwu \& Sharaf (t. Cet; Semarang: C.V. Toha Putra, 1970), h. 6

Semua kalimat huruf itu mabni, begitu juga semua fi'il madhi dan semua fi'il amr. 
c) Bentuk jama'(frural/lebih dari dua)

\begin{tabular}{|c|c|}
\hline الترجمة & الجملة \\
\hline $\begin{array}{l}\text { 1. para ustadz dan mahasiswa adalah } \\
\text { bersaudara }\end{array}$ & 1 ا إخوةٌ \\
\hline $\begin{array}{l}\text { 2. sesungguhnya para ustadz dan mahasiswa } \\
\text { bersaudara }\end{array}$ & 2 إخوُّ الأستاذينِ و الطالبين \\
\hline $\begin{array}{l}\text { 3. ya Allah apunilah para ustadz dan } \\
\text { mahasiswa }\end{array}$ & 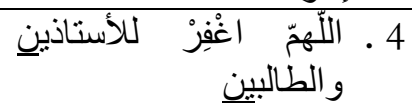 \\
\hline
\end{tabular}

Dari beberapa bentuk contoh kalimat diatas baik bentuk mufrad (tunggal), muśanna (dua), maupun jama' (flural) terjadi perubahan pada lafalnya sesuai kedudukannya dalam suatu kalimat (jumalah).

Contoh kalimat mabnī:

a) Ism dhamīr

\begin{tabular}{|c|c|}
\hline الترجمة & الجملة \\
\hline 1. dia hamba yang pemurah & 1 ـ هوُعبدُ الكَريم \\
\hline 2. dia bukan hamba yang pemurah & 2 ـ لَيْسَ هوُ عبدُ الكَريم \\
\hline 3. dari dia hamba yang mulia & 3. مِنْ هوُ عبدُ الكَريم \\
\hline
\end{tabular}

b) Ism Isyarah (kata penunjuk)

\begin{tabular}{|c|c|}
\hline الترجمة & 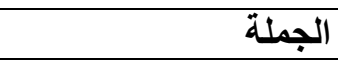 \\
\hline 1. ini koran & 1 ـ ـذَهِ جَرِيْدَةُ \\
\hline 2. saya sudah baca koran ini & 2. قَرََأُتُ هذهِ جريدَةً \\
\hline 3. di sini terdapat kisah-kisah & 3 ـ في هذهِ قِصنصِ \\
\hline
\end{tabular}

Didalam Bahasa Arab ada lafal yang bacaan huruf terakhirnya tetap, tidak berubah-ubah seperti lafal: هو- هذه - أين - من- كتب . lafal-lafal ini pada permulaan, susunan jumlah, bacaan hurufnya yang terakhir tetap, tidak berubah. Lafal-lafal semacam ini dinamakan : لَفْظُ مبنيٌ (lafal mabni). ${ }^{13}$ Sebagaimana pada contoh dalam dua (2) tabel (ism dhamī dan ism isyarah) diatas

Contoh Kalimat الضمير المنفصل (kata ganti yang tidak bersambung)

1) Kata ganti orang ke-III : orang yang dibicarakan, yaitu:

\begin{tabular}{|c|c|}
\hline الترجمة & الجملة \\
\hline 1. Dia mahasiswa & 1 ـ هو طَالِبٌ \\
\hline 2. Mereka berdua mahasiswa & 2 ـ . هما طالبان \\
\hline 3. Mereka mahasiswa & 3. هم طلاب \\
\hline
\end{tabular}

${ }^{13}$ Lihat Irbabullubab dan Dja'far Ami, h. 5 
Website: https://journal.stiba.ac.id

ISSN : 2685-7537 (online) 2338-5251 (Printed)

\begin{tabular}{|l|c|}
\hline 4. Dia mahasiswi & هي طالبة 4 \\
\hline 5. Mereka berdua mahasiswi & هما طالبنان 6 \\
\hline 6. Mereka Mahasiswi & هنّ طالبات \\
\hline
\end{tabular}

2) Kata ganti orang ke-II : orang yang diajak bicara, yaitu:

\begin{tabular}{|c|c|}
\hline الترجمة & الجملة \\
\hline 1. Kamu seorang muslim & 1 ـ أنتََ مُسْْلمِ \\
\hline 2. Kalian berdua muslim & 2 ـ ـ أنتُها مُسْلِمانِ \\
\hline 3. Kalian muslim & 3 ـ ـ أنتُمْ مُسلمِوْنَنَ \\
\hline 4. Kamu muslimah & 4 ـ أَنْتِ مسلمَةٌُ \\
\hline 5. Kalian berdua muslimah & 5 ـ أنتُما مُسلِلمَتَانِ \\
\hline 6. Kalian muslimah & 6 ـ ـ أنتنَّ مُسلِماتُ \\
\hline
\end{tabular}

3) Kata ganti orang ke-I : orang yang berbicara, yaitu :

\begin{tabular}{|c|c|}
\hline الترجمة & لجملة \\
\hline 1. Saya seorang muslim & 4 ـ ـ أنا مُسنِلِمِ \\
\hline 2. Kami muslim & 5 ـ ـَــــــنُ مُسْلْمَوْنَ \\
\hline
\end{tabular}

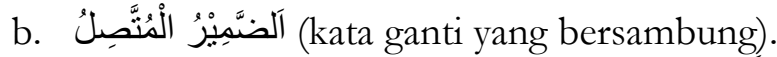

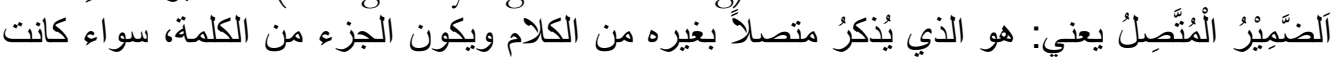

Dhamìr Muttașil yaitu dhamīr yang disebutkan secara bersambung dengan lafal lain dari suatu kalimat dan merupakan bagian dari kalimat tersebut, baik kata benda, kata kerja atau kata bantu. ${ }^{14}$

Contoh Kalimat الضمير المتصل (kata ganti yang tidak bersambung). Ada yang bersambung dengan ism dan ada yang bersambung dengan fi'il.

1) Contoh bersambung denagan ism.

Dhamìr Göib (kata ganti orang ke-III) : orang yang dibicarakan

\begin{tabular}{|c|c|c|c|c|}
\hline التّرجمة & الاسم والضمير & الضَبِّيِّ & الضنفَِيرل & رَقم \\
\hline bolpoinnya [1] & قَلَمَُهُ & 。 & هو & 1 \\
\hline $\begin{array}{l}\text { bolpoinnya mereka berdua } \\
\text { []] }\end{array}$ & قَلَكُهُهَمَا & هما & Los & 2 \\
\hline bolpoinnya mereka [l] & قَلَلَعُهُمْ & هم & هم & 3 \\
\hline
\end{tabular}
2018).

${ }^{14}$ http://forums.way2allah.com/forum/شرح-مبسط-للضمائر-المنفصلة-والمتصلة (diakses tanggal, 8 Februari 
NUKHBATUL 'ULUM : Jurnal Bidang Kajian Islam

Vol. 4, No. 1 (2018) : Hal. $61-69$

Website: https://journal.stiba.ac.id

ISSN : 2685-7537 (online) 2338-5251 (Printed)

\begin{tabular}{|c|c|c|c|c|}
\hline bolpoinnya [p] & قَلَكَهُهُمَا & ها & 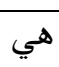 & 4 \\
\hline $\begin{array}{l}\text { bolpoinnya mereka berdua } \\
\text { [p] }\end{array}$ & قَلَكُهُهُمَا & خما & هol & 5 \\
\hline bolpoinnya mereka [p] & لََلَمَهُنَّن & هنّ & هنّ & 6 \\
\hline
\end{tabular}

Dhamīr Mukhätab (Kata ganti orang ke-II) : orang yang diajak bicara

\begin{tabular}{|c|c|c|c|c|}
\hline التّرجمة & الاسم والضتصير & الضَتِيِير صل & الضَفِمِلر & رَقم \\
\hline Bolpoinnya kamu [1] & 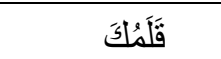 & كَ & أَنْتَ & 1 \\
\hline Bolpoinnya kalian berdua [1] & قَلَمُكُمَا & كُما & أَنْتُما & 2 \\
\hline Bolpoinnya kalian [1] & قََلَمَكُْْْ & كُْْ & أَنْتُُْ & 3 \\
\hline Bolpoinnya kamu $[\mathrm{p}]$ & قََلَمَاكِ & كِ & أَنْتِت & 4 \\
\hline Bolpoinnya kalian berdua [p] & قَلَكَكُمَا & كُما & أَنْتُما & 5 \\
\hline Bolpoinnya kalian [p] & قَلَكَكُكُنَّ & كُنَّ & أَنْتُنُّ & 6 \\
\hline
\end{tabular}

Dhamīr Mutakallim (Kata ganti orang ke-I) : orang yang berbicara

\begin{tabular}{|c|c|c|c|c|}
\hline التّرجمة & الاسم والضمير & الضَمِيِّل & الضنفَمِلر & رَقَم \\
\hline Bolpoinnya kamu [1] & قَلَمِيَ & يْ & أنانا & 1 \\
\hline Bolpoinnya kalian berdua [1] & قَلَمُنَا & نَا & نَحْنُ & 2 \\
\hline
\end{tabular}

2) Contoh bersambung dengan fi'il

Dhamīr Göib (kata ganti orang ke-III) : orang yang dibicarakan

\begin{tabular}{|c|c|c|c|c|}
\hline التزّجمة & الفعل و الضتصير & الضَبِيِّ & المنفِصِير & رَقَم \\
\hline Allah mengampuninya [1] & غَفَرَهُ الله & 。 & هو & 1 \\
\hline $\begin{array}{l}\text { Allah mengampuni mereka } \\
\text { berdua [l] }\end{array}$ & غَفَرَ هُمَا الله & هما & Los & 2 \\
\hline Allah mengampuni mereka [1] & الله غَفَرَ هُمْ & هم & هم & 3 \\
\hline Allah mengampuninya [p] & غَفَرَهَا الله & ها & هي & 4 \\
\hline $\begin{array}{l}\text { Allah mengampuni mereka } \\
\text { berdua }[\mathrm{p}]\end{array}$ & غَفَرَ هُهَا الله & خما & Lot & 5 \\
\hline Allah mengampuni mereka [p] & الله غَفَرَهُنَّ & 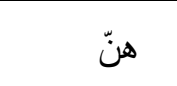 & هنّ & 6 \\
\hline
\end{tabular}

Dhamīr Mukhätab (Kata ganti orang ke-II) : orang yang diajak bicara

\begin{tabular}{|c|c|c|c|c|}
\hline التّرجمة & الاسم والضميز & الضَمِيّر المل & الضنفمِيل & رَقم \\
\hline Allah mengampuni kamu [1] & غَفَرَكَكَ الله & كَ & أَنْتَتَ & 1 \\
\hline
\end{tabular}


NUKHBATUL 'ULUM : Jurnal Bidang Kajian Islam

Vol. 4, No. 1 (2018) : Hal. $61-69$

Website: https://journal.stiba.ac.id

ISSN : 2685-7537 (online) 2338-5251 (Printed)

\begin{tabular}{|c|c|c|c|c|}
\hline $\begin{array}{l}\text { Allah mengampuni kamu berdua } \\
\text { [1] }\end{array}$ & الله غَفَركَمَا & كُمَا & أَنْمُما & 2 \\
\hline Allah mengampuni kalian [1] & غَفَرَكُْْ الله & كُْْ & أَنْنُْْ & 3 \\
\hline Allah mengampuni kamu [p] & غَفَرَكَ الله & ك) & أَنْتِتِ & 4 \\
\hline $\begin{array}{l}\text { Allah mengampuni kamu berdua } \\
\text { [p] }\end{array}$ & غَفرَكَّا الله & كُما & أنَتُما & 5 \\
\hline Allah mengampuni kalian [p] & اللَ غَفرَكنَّ & 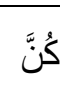 & أَنْنُنَّ & 6 \\
\hline
\end{tabular}

Dhamīr Mutakallim (Kata ganti orang ke-I) : orang yang berbicara

\begin{tabular}{|c|c|c|c|c|}
\hline التّرجمة & الاسم والضميز & الضَمِيّر & الضنفِيلِ & رَقم \\
\hline Allah mengampuni saya $[1 / \mathrm{p}]$ & الله غَفَرَنِيَ & يْ & أنَا & 1 \\
\hline Allah mengampuni kita $[1 / \mathrm{p}]$ & غَغَرَنَا الله & نَا & نَحْنُ & 2 \\
\hline
\end{tabular}

\section{PENUTUP}

Dari pembahasan di atas, maka dapat ditarik beberapa kesimpulan dari tulisan ini yang dijabarkan dalam beberapa poin antara lain:

1. Bahasa Arab adalah bahasa yang sarat dengan kaidah-kaidah (qawäid) dan diantara kaidah tersebut adalah kaidah sharf yang harus diketahui bagi setiap orang yang mau mempelaji Bahasa Arab.

2. Dari berbagai pengertian akan makna dhamīr atau dhamaìr maka penulis condong untuk memilih makna dhamì $r$ yaitu kata yang menunjukkan sebagai sifat, atau kata ganti orang pertama (mutakallim), atau kata ganti orang ke dua (mikhätab), atau kata ganti orang ke tiga (gäib), sebagai kata ganti benda (berakal atau tidak berakal) untuk meringkas suatu kalimat.

3. Dhamīr atau kata ganti terdiri dari empat belas (14) antara lain:

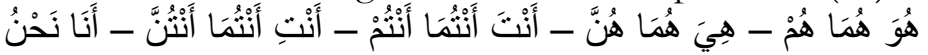

4. Selain sebagai kata ganti, dhamìr dijadikan acuan untuk perubahan bentuk fi'il (kata kerja).

5. Secara umum dhamīr terbagi menjadi dua (2) yaitu: dhamīr munfașil (kata ganti yang tidak bersambung) dan dhamīr muttașil (kata ganti yang tersambung).

6. Bentuk-bentuk dhamīr antara lain: dhamìr mufrad (satu/tunggal), dhamīr muanns (dua), dan dhamīr jama' (flural/lebeh dari dua).

7. Kata dari segi fungsinya terbagi dua yaitu: mu'rab dan mabnī

- Mabnī yaitu kata yang akhirnya tetap pada satu keadaan/bacaan didalam segala susunan jumlah.

- Mu'rab yaitu kata yang berubah-ubah akhirnya atau kata yang tanda baca akhirnya berubah sesuai kedudukannya pada suatu kalimat.

\section{DAFTAR PUSTAKA}

Salim bin Subaid, Abu Abdillah. Tegal : Ash-Shafmedia, 2008. 
NUKHBATUL 'ULUM : Jurnal Bidang Kajian Islam

Vol. 4, No. 1 (2018) : Hal. $61-69$

Website: https://journal.stiba.ac.id

ISSN : 2685-7537 (online) 2338-5251 (Printed)

Tsani Djali, Asri Ibnu. Sharf Lughatuna Cet. II; asripublisher Jawa Barat, 2010.

Abu Razin dan Ummu Razin, Ilmu Sharaf Untuk Pemula Cet.III; Jakarta: Maktabah BISA, 2017.

Ni'mah, Fuād. Mulahkas Qawāid al-Lugah al-Arabiyyah t. Cet: Beirut: Dār At-Śqāfah AlIslāmiyyah.

http://mawdoo3.com.

http://forums.way2allah.com/forum

Irbabullubab dan Dja'far Amir, Nahwu \& Sharaf t. Cet; Semarang: C.V. Toha Putra, 1970.

Abdul Hamid, Muhammad Muhhyidin. At-Tuhfa As-Saniyah (syarah Ajurumiyah).

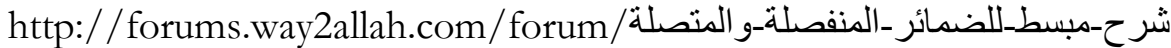

